\title{
(6) OPEN ACCESS \\ Awareness and determinants of electronic cigarette use among Finnish adolescents in 2013: a population-based study
}

\author{
Jaana Maarit Kinnunen, ${ }^{1}$ Hanna Ollila ${ }^{2}$ Salma El-Tayeb El-Amin, ${ }^{1}$ Lasse Antero Pere, ${ }^{1}$ \\ Pirjo Liisa Lindfors, ${ }^{1}$ Arja Hannele Rimpelä ${ }^{1,3}$
}

\begin{abstract}
${ }^{1}$ School of Health Sciences, University of Tampere, Tampere, Finland ${ }^{2}$ Department of Alcohol, Drugs and Addiction, National Institute for Health and Welfare, Helsinki, Finland ${ }^{3}$ Department of Adolescent Psychiatry, Pitkäniemi Hospital Nokia, Tampere University Hospital, Tampere, Finland
\end{abstract}

\section{Correspondence to} Jaana Kinnunen, School of Health Sciences, University of Tampere, Tampere FI-33014, Finland; jaana.m.kinnunen@uta.fi

Received 22 December 2013 Revised 14 April 2014 Accepted 30 April 2014 Published Online First 14 May 2014
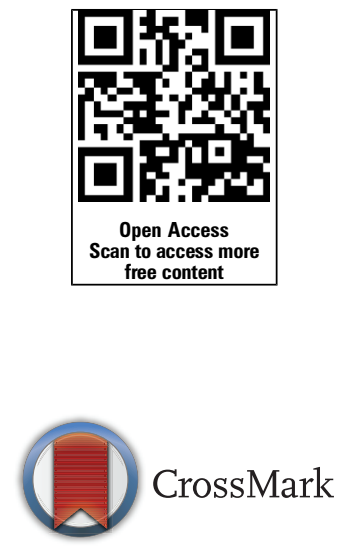

To cite: Kinnunen JM Ollila H, El-Amin SE-T, et al. Tob Control 2015;24 e264-e270.

\section{ABSTRACT}

Background A wide range of electronic cigarettes (e-cigarettes) are now on the market. We studied e-cigarette awareness and use, determinants and sources of e-cigarettes, the e-liquids used in them and exposure to e-cigarette advertisements among adolescents in Finland. Among smokers, we studied the association of e-cigarette use and interest in smoking cessation.

Method Data were obtained from a national survey of 12-18-year-old Finnish adolescents in 2013 ( $N=3535$, response rate 38\%). Descriptive statistics and logistic regression analysis were used.

Results Of the respondents, $85.3 \%$ knew what ecigarettes were; $17.4 \%$ had tried them. E-liquids with nicotine were used most often (65.7\%); also those who had never tried conventional cigarettes had used them. Of e-cigarette ever users, 8.3\% had never tried smoking. Parents' high level of education, being in employment, and intact family protected against children's e-cigarette use. In the final model, daily smoking (OR 41.35; $95 \% \mathrm{Cl}$ 25.2 to 67.8$)$, snus use $(2.96 ; 2.4-4.0)$, waterpipe use $(2.21 ; 1.6-3.0)$, children's vocational education (2.06; 1.4-3.1) and poor school performance $(1.92 ; 1.4-3.0)$ were associated with e-cigarette experimentation. Those smokers with most experience of e-cigarettes were least likely to consider smoking cessation.

Conclusions Awareness and experimentation with e-cigarettes are high among adolescents, especially in older age groups and boys. Nicotine e-liquids are easy to acquire for youth. Having similar risk factors, e-cigarette use seems to follow the model of conventional smoking initiation. Among adolescent smokers, use of e-cigarettes does not clearly relate to interest in smoking cessation. Preventive policies are needed to protect the youth.

\section{BACKGROUND}

In recent years, the rise of a new tobacco-like product, the electronic cigarette (e-cigarette) or electronic nicotine delivery system (ENDS),${ }^{1}$ has raised concerns. Despite the name, these products do not contain tobacco or necessarily resemble a conventional cigarette, and there are also nonnicotine product lines, sometimes called e-shishas. These products vaporise liquid solution (e-liquid, 'e-juice') composed of propylene glycol and other chemicals, which is then inhaled. ${ }^{2}$

E-cigarettes are marketed with claims, so far unproven, of efficacy in smoking cessation. ${ }^{2-4}$ Instead of mimicking the appearance of nicotine replacement therapy (NRT) products, e-cigarettes often use colour coding and flavours familiar from contemporary cigarette packets. ${ }^{5}$ Recently, traditional tobacco companies have emerged openly onto the market. Questions have been raised as to whether e-cigarettes are purely a new tactic for renormalising smoking in the context of declining use of conventional cigarettes. $^{6}$ The wide variety of e-cigarettes has drawn attention to their potential appeal for young people: the products come in multiple colours, shapes and flavours.

Regarding accessibility to youth, e-cigarettes have different legal status in different countries. Often they fall into a grey area of jurisdiction. ${ }^{1}$ In Finland, selling tobacco products to individuals under 18 years old is prohibited, but as e-cigarettes are categorised as tobacco imitations, and e-liquids as substitute tobacco, minors can purchase them. E-cigarettes and e-liquids are treated as medicinal products if they contain nicotine. Products containing over $0.42 \mathrm{~g}$ nicotine/product or $10 \mathrm{mg} /$ cartridge are treated as prescription medicines, while products with lower nicotine content are treated as over-the-counter medicines. No e-cigarette company holds a permit for selling nicotine-containing e-liquids in Finland because they have not demonstrated the required safety and efficacy evidence for medicinal products. However, consumers, including adolescents, can acquire nicotine-containing liquids from visits abroad or online cross-border distance sales.

The marketing of e-cigarettes is currently vast. ${ }^{67}$ Lessons from conventional tobacco show that marketing is a risk factor for smoking initiation. ${ }^{8}$ Active marketing efforts take place especially on the internet and social media-popular channels among youth, but challenging to supervising authorities. ${ }^{9}$ In Finland, a legislative ban on direct and indirect advertising applies to e-cigarettes, but a point-of-sale display ban covers only tobacco products and their trademarks.

Little is known about the safety and health effects of these products, but the number of studies is growing. E-liquids have been shown to contain small amounts of harmful substances (eg, carcinogenic nitrosamines, toxic diethylene glycol). ${ }^{10}$ The quality of e-liquids and electronic appliances has been shown to vary, and stated ingredient lists have not corresponded to actual ingredients. ${ }^{12} 1112$ As the business has grown, however, there is some evidence that the quality may have improved. ${ }^{13}$ Some short-term negative health effects for the respiratory system have been reported, ${ }^{14}$ but long-term effects remain uncertain.

For adolescents, use of nicotine-containing e-liquids constitutes a risk for developing dependence. Nicotine may have a lasting effect on the 
developing brain, due to its plasticity in adolescence. ${ }^{15}$ Based largely on animal studies, adolescents may be expected to experience enhanced short-term positive and reduced aversive effects of nicotine, and fewer negative effects during nicotine withdrawal, compared with adults. ${ }^{16}$ This is due to the brain being in a developmental phase, when dopamine-facilitating systems are overdeveloped and inhibitory systems underdeveloped, ${ }^{16}$ which can explain why some adolescents show signs of nicotine dependence after brief intermittent use. ${ }^{17}$

There are only a few studies on use of e-cigarettes among adolescents. In 2011, 9.4\% of South Korean adolescents reported having used e-cigarettes, $4.7 \%$ during the past 30 days and $1.4 \%$ without previous use of conventional cigarettes. ${ }^{18}$ In Poland, $86.4 \%$ of students aged $15-24$ years had heard about e-cigarettes in 2010-2011, and 23.5\% of individuals aged 15-19 years had used e-cigarettes, $8.2 \%$ during the previous month. ${ }^{19}$ Of never-smoking students, $3.2 \%$ had used them. ${ }^{19}$ In the USA, the National Youth Tobacco Survey showed that e-cigarette ever use and recent use doubled among middle and high school students during 2011-2012. ${ }^{20}$ The increase was strongest among high school students, in whom the ever use of e-cigarettes doubled from $4.7 \%$ to $10 \%$. The same study showed that $20.3 \%$ of middle school e-cigarette users and $7.2 \%$ of high school users had never smoked a conventional cigarette. ${ }^{20}$ Another US study showed that the prevalence of using an e-cigarette in the past 30 days more than doubled among high school students over a 16 -month period, from $0.9 \%$ in 2010 to $2.3 \%$ in $2011 .^{21}$

E-cigarette use in adolescence is strongly linked to ever or current tobacco smoking ${ }^{18-21}$ and male gender. ${ }^{18} 19$ In addition, associations have been found with older age and attempts to quit during the past year. ${ }^{18}$ Interest in the product seems to relate to general attitudes towards smoking: non-smokers who have more negative beliefs about the typical smoker were less willing to try e-cigarettes. ${ }^{22}$

In general, awareness and use of e-cigarettes has increased rapidly in different parts of the world. ${ }^{23}$ In Finland, the awareness of e-cigarettes among adults has been the highest (64\%) in the EU, but actual use has remained marginal (current use 2\%), including as an aid to smoking cessation $(5 \%) .{ }^{24}$ In this study, we publish the first results concerning awareness and use of e-cigarettes and types of e-liquids used among Finnish adolescents aged 12-18 years, based on nationally representative data. To deepen and extend previous findings, we also studied adolescents' sources of e-cigarettes, exposure to e-cigarette advertising, and the association of e-cigarette use with interest in smoking cessation among daily smokers. Furthermore, because e-cigarettes seem to relate strongly to concurrent conventional tobacco smoking in adolescence, we test the hypothesis that e-cigarette use relates to other tobacco use in general and shares similar risk factors to conventional smoking initiation.

\section{METHODS}

\section{Sampling and participants}

We used 2013 data from the nationwide monitory system on adolescent health and health behaviours, the Adolescent Health and Lifestyle Survey. This is a cross-sectional postal survey, with an option to answer securely online, conducted biennially in Finland since 1977 by the University of Tampere. Nationally representative samples of individuals aged 12, 14, 16 and 18 years were obtained from the national Population Register Centre (http://vrk.fi/default.aspx? site=4). All Finns born on sample days in June, July or August in each age group were selected. This minimised the age variation within age groups.
The Ethics Committee of the Tampere region approved the study protocol: filling in the questionnaire was considered as adolescents' consent to participate. No parental consent was requested.

Self-administered questionnaires in official languages (Finnish/ Swedish) were sent to 9398 adolescents in February, followed by three reminders to non-responders. The number of responders to the questionnaire was 3535 (response rate 38\%; including 1405 boys and 2130 girls). A short questionnaire, including the main questions on tobacco, was sent with the third reminder to the non-responders, of whom 623 responded to the short questionnaire; these responses were used for comparison of responders and non-responders.

\section{Study measures}

Awareness and use of e-cigarettes was assessed via the questions: 'Have you ever tried electronic cigarettes? How many times altogether?' Options were: 'I do not know what they are', 'No', 'I have tried once or twice', 'I have tried 20 times or less', 'I have tried more than 20 times'. The question on e-liquid content was: 'If you have used electronic cigarettes, what substance did they contain?', with the options 'Liquid with nicotine', 'Liquid without nicotine', 'I do not know'. The respondent could report several liquids. Sources of e-cigarettes were established via an open-ended question: 'If you have used electronic cigarettes, where did you get them?' The 29 different responses were categorised into six sources (see table 3 ). The question about exposure to e-cigarette advertising was: 'During the past month, have you seen an electronic cigarette advertisement in Finland?' The alternatives were 'No', 'Yes'. Those who answered 'Yes' were asked 'Where?' Thirty different responses were categorised into six groups: Facebook, other internet pages, traditional media, shops, the street, and elsewhere. Interest in quitting smoking was assessed by asking current smokers: 'Have you thought about trying to quit smoking in the near future?', with the options 'No', 'Yes'.

Smoking status was divided into three groups: never-smokers (never tried conventional cigarettes), experimenters (tried but did not smoke daily), and daily smokers (reported daily smoking and smoked $>50$ cigarettes in lifetime). Snus and waterpipe use were dichotomised (tried, not tried). Parents' smoking was asked separately and categorised as neither smokes, only mother smokes, only father smokes, both smoke. Attitude towards conventional cigarette smoking was assessed by posing the statement: 'Smoking is for losers' (which has been used previously in the survey), with the options definitely agree, agree to some extent, difficult to say, slightly disagree, definitely disagree. School type was categorised as comprehensive, general upper secondary, vocational upper secondary, combined general and vocational upper secondary, other schools, not in school. (The last two categories were combined due to their small sizes.) School performance was based on the respondent's subjective assessment of school performance compared with the class average: 'much or slightly better', 'about class average', and 'slightly or much poorer'. Family structure was dichotomised according to whether the respondent lived with both parents (intact family) or not (other). Parents' education was asked separately and categorised into one variable (highest educational level of either parent): 'high' (over 12 years of education), 'middle' (9-12 years), and 'low' (9 years or less). Father's and mother's work situations were dichotomised: 'working', 'not working', the latter including both unemployed and retired. The proportion of missing answers was small for all variables $(0.4-7.9 \%)$. 
Table 1 Distribution of e-cigarette use among adolescents in Finland in 2013 by sex and age, \%. The total columns are adjusted for age or age and sex

\begin{tabular}{|c|c|c|c|c|c|c|c|c|c|c|c|}
\hline \multirow[b]{2}{*}{ Use of e-cigarettes $\mid$ Age } & \multicolumn{5}{|l|}{ Girls } & \multicolumn{5}{|l|}{ Boys } & \multirow{2}{*}{$\begin{array}{l}\text { All } \\
\text { Tota }\end{array}$} \\
\hline & 12 & 14 & 16 & 18 & Total & 12 & 14 & 16 & 18 & Total & \\
\hline Do not know what they are & 43.8 & 13.3 & 7.2 & 3.2 & 16.9 & 29.3 & 9.9 & 4.9 & 5.8 & 12.5 & 14.7 \\
\hline Never tried & 55.9 & 74.5 & 72.7 & 73.2 & 69.1 & 68.4 & 70.6 & 66.6 & 62.8 & 67.1 & 68.1 \\
\hline Have tried once or twice & 0.3 & 9.1 & 15.3 & 18.4 & 10.8 & 1.6 & 15.3 & 19.5 & 20.6 & 14.3 & 12.6 \\
\hline Have tried 20 times or less & - & 2.5 & 3.2 & 3.7 & 2.4 & 0.8 & 3.2 & 3.7 & 5.1 & 3.2 & 2.8 \\
\hline Have tried more than 20 times & - & 0.7 & 1.7 & 1.6 & 1.0 & - & 1.0 & 5.3 & 5.8 & 3.0 & 2.0 \\
\hline Total & 100 & 100 & 100 & 100 & & 100 & 100 & 100 & 100 & & \\
\hline $\mathrm{N}$ & 288 & 596 & 596 & 626 & 2106 & 256 & 405 & 431 & 277 & 1369 & 3475 \\
\hline
\end{tabular}

\section{Analysis of non-responders}

Boys were underrepresented among the responders $(40.6 \%)$ compared with the sample (50.7\%). For age, adolescents aged 12 years were overrepresented $(16.3 \%$ vs $13.5 \%)$ and those aged 18 years underrepresented $(25.7 \% ; 30.4 \%)$ while differences were small for those aged 14 years $(27.6 \% ; 28.9 \%)$ and 16 years $(28.5 \% ; 29.2 \%)$. The impact of non-response was assessed by comparing those who responded to the full questionnaire $(n=3535)$ with those who responded to the short questionnaire $(n=623)$ which was sent to three-time nonresponders. (It was assumed that this latter group closely represented all non-responders.) E-cigarette use did not differ between the groups (Pearson's $\chi^{2}$ test, $p=0.502$ ), neither did age $(p=0.216)$, but boys were more likely to be non-responders $(p=0.01)$. For boys, school type $(p=0.323)$ and school performance $(p=0.926)$ did not differ between the groups. Girls studying in vocational upper secondary school were more likely to be classed as non-responders compared with girls in general upper secondary school $(p=0.000)$, as were those with average or worse school performance $(p=0.001)$.

\section{Data analysis}

Awareness and use of e-cigarettes and e-liquids were cross tabulated with age, sex, tobacco use and socioeconomic background. Age-adjusted and sex-adjusted prevalence was calculated using direct adjustment giving equal weights to each group. For 12-year-old adolescents, only results for use and awareness are presented because their e-cigarette use was rare. Sources of e-cigarettes are presented for those who had used e-cigarettes, and advertisement locations for those who had seen them. Interest in smoking cessation in relation to e-cigarette use was analysed among daily smokers.
Factors associated with ever use of e-cigarettes were analysed using stepwise logistic regression analysis. The analysis was first conducted separately for all independent variables, adjusting for age and sex. All independent variables were then included in a multivariate model. Results are presented as ORs and 95\% CIs. The Pearson $\chi^{2}$ test was used to test for statistical significance. Data were analysed using IBM SPSS Statistics, V.20.

\section{RESULTS}

\section{Awareness and use of e-cigarettes}

Awareness of e-cigarettes was high: $85.3 \%$ of $12-18$-year-old adolescents reported knowing what e-cigarettes are. Awareness was lowest among the youngest and highest among the oldest age groups (table 1). Overall, 17.4\% of the respondents had tried e-cigarettes, although most of them (12.6\%) had experimented only once or twice. The proportion who had used e-cigarettes more than 20 times was 2.0\%. Experimentation with e-cigarettes increased by age for both sexes, and in each age group experimentation was more common among boys.

\section{Content of e-liquids}

Use of nicotine e-liquids was common: $65.7 \%$ of e-cigarette ever users reported this (table 2). Every fourth ever user had used only liquids without nicotine, and every tenth person did not know the content of the liquid.

Of those who had used e-cigarettes more than two times, 83.6\% had used liquids containing nicotine. Of those who had tried e-cigarettes only once or twice, the proportion was $59.4 \%$. All those who had used e-cigarettes more than 20 times knew what e-liquids they had used: the highest proportion $(14.3 \%)$ of those who did not know the content of e-liquids was among those who had tried e-cigarettes only once or twice.

Table 2 E-cigarette ever users by type of e-cigarette liquid, and the proportion of e-cigarette ever users in each e-liquid category who had never tried conventional cigarettes

\begin{tabular}{|c|c|c|c|c|c|c|}
\hline & \multicolumn{6}{|c|}{ Type of e-liquid } \\
\hline & \multicolumn{2}{|c|}{ With nicotine } & \multicolumn{2}{|c|}{ Without nicotine } & \multicolumn{2}{|c|}{ Did not know } \\
\hline & $\mathbf{n}$ & $\begin{array}{l}\% \\
95 \% \mathrm{Cl}\end{array}$ & $\mathrm{n}$ & $\begin{array}{l}\% \\
95 \% \mathrm{Cl}\end{array}$ & $N$ & $\begin{array}{l}\% \\
95 \% \mathrm{Cl}\end{array}$ \\
\hline E-cigarette ever users, all & 411 & $\begin{array}{l}65.7 \% \\
61.8 \text { to } 69.3 \%\end{array}$ & 147 & $\begin{array}{l}23.5 \% \\
20.3 \text { to } 27.0 \%\end{array}$ & 68 & $\begin{array}{l}10.9 \% \\
8.7 \text { to } 13.5 \%\end{array}$ \\
\hline $\begin{array}{l}\text { Proportion of e-cigarette ever users who had never tried } \\
\text { conventional cigarettes in each e-liquid category }\end{array}$ & 12 & $\begin{array}{l}2.9 \% \\
1.7 \text { to } 5.0 \%\end{array}$ & 31 & $\begin{array}{l}21.1 \% \\
15.3 \text { to } 28.4 \%\end{array}$ & 9 & $\begin{array}{l}13.2 \% \\
7.1 \text { to } 23.3 \%\end{array}$ \\
\hline
\end{tabular}


Table 3 Sources of e-cigarettes among adolescent e-cigarette ever users who reported a source, $\%(95 \% \mathrm{Cl})(\mathrm{N}=517)$ *

\begin{tabular}{lcl}
\hline Source of e-cigarettes & $\%$ & $\mathbf{( 9 5 \% ~ C l )}$ \\
\hline Friends & 79.9 & $(76.2$ to $83.1 \%)$ \\
Internet & 7.2 & $(5.2$ to $9.7 \%)$ \\
Family & 5.0 & $(3.5$ to $7.3 \%)$ \\
Abroad & 3.3 & $(2.1$ to $5.2 \%)$ \\
Shop & 1.7 & $(0.9$ to $3.4 \%)$ \\
Other place & 4.1 & $(2.7$ to $6.5 \%)$ \\
\hline
\end{tabular}

${ }^{*}$ A person may have reported more than one source.

Of all e-cigarette ever users, $8.3 \%$ had never tried tobacco smoking. Of those who used nicotine-containing e-liquids, 2.9\% were never smokers (table 2). Of those $8.3 \% \quad(n=52)$ of e-cigarette users who had never tried tobacco smoking, 12 had used nicotine-containing e-liquid, 31 had used only liquids without nicotine and 9 did not know what the liquid was.

\section{Sources of e-cigarettes and exposure to e-cigarette advertising}

E-cigarette ever users were asked about the source of their e-cigarettes (table 3). Almost $80 \%$ reported friends as their primary source, with acquisition from the internet (7.2\%) as the second most common source.

During the previous month, $10.5 \%$ of respondents had seen e-cigarette advertisements. Of those, $21.8 \%$ had seen them on Facebook, $41.4 \%$ on other internet pages, $14.7 \%$ in shops, $7.4 \%$ in magazines or on television, $4.9 \%$ in the street and 7.1\% elsewhere.

\section{Interest in quitting smoking}

Among adolescent daily smokers, $74.1 \%$ had considered quitting smoking in the near future. Adolescents aged 14-18 years with more frequent e-cigarette experimentation were less likely to consider quitting smoking (table 4). Among daily smokers who had tried e-cigarettes more than 20 times, 55.3\% had considered quitting tobacco smoking; this dropped to $48.6 \%$ among heavier smokers (10 or more cigarettes per day). Of those daily smokers who had tried e-cigarettes only once or twice, three out of four had considered quitting.

\section{Factors associated with e-cigarette use}

In model 1 (adjusted for age and sex), all tobacco-related and socioeconomic background variables had a significant association with e-cigarette experimentation (table 5). The strongest associations were observed for daily smoking, followed by snus and waterpipe use.

Parents' smoking, exposure to e-cigarette advertisements and having a positive attitude towards conventional smoking were all positively associated with e-cigarette experimentation. Among socioeconomic characteristics, type of school and school performance were more strongly related to e-cigarette use than family structure, parents' education and parents' work situation. High parental education, being in employment and intact family protected against children's e-cigarette use.

In the final model (model 2, table 5), adjusting for all variables, e-cigarette use showed the strongest association with conventional smoking, followed by snus and waterpipe use. Among socioeconomic characteristics, only vocational education and having poor school performance retained a significant association with e-cigarette use.

\section{DISCUSSION}

The results of our study demonstrate that awareness and ever use of e-cigarettes are high among adolescents, especially in older age groups and boys. E-cigarettes are also used by those who have never smoked conventional tobacco, although the majority of ever users are daily smokers. E-liquids used by adolescents typically contain nicotine. Friends are the main source of acquisition, followed by the internet. Despite the advertisement ban, every 10th adolescent reported having seen e-cigarette advertisements, mostly on Facebook. Use of other tobacco products, parents' smoking and lower socioeconomic background, and the adolescents' vocational education and poor school performance were associated with ever use of e-cigarettes. Among daily smokers, interest in smoking cessation was least common among those with the highest level of e-cigarette experimentation.

Our study found levels of e-cigarette awareness comparable to a recent Polish study, in which nearly nine out of ten adolescents had heard of e-cigarettes. ${ }^{19}$ The proportion of Finnish adolescents who had tried e-cigarettes was comparable to that in Poland, ${ }^{19}$ but higher than that reported in Korea and the USA. ${ }^{18} 20{ }^{21}$ Previous studies have reported significant increases in adolescents' e-cigarette use over the short term. ${ }^{18} 2021$ These findings are likely to reflect the rapid growth in product availability and marketing in recent years, ${ }^{6} 7$ but also different regulatory approaches in these countries.

Our results showing higher use of e-cigarettes in male adolescents, conventional smokers and older age groups are in line with previous studies. ${ }^{18} 19$ The finding that those adolescents with positive attitudes towards conventional smoking have higher ever use of e-cigarettes also supports previous results regarding willingness to try e-cigarettes. ${ }^{22}$ In addition, the

Table 4 Percentage and $95 \% \mathrm{Cl}$ of those who had considered quitting tobacco smoking in the near future, according to e-cigarette use, among all 14-18-year-old daily smokers and among those who smoke $\geq 10$ cigarettes daily

\begin{tabular}{|c|c|c|c|c|c|c|}
\hline \multirow[b]{3}{*}{ Use of e-cigarettes } & \multicolumn{3}{|c|}{ Considered quitting smoking } & & & \\
\hline & \multicolumn{3}{|c|}{ All daily smokers } & \multicolumn{3}{|c|}{ Daily smokers, $\geq 10$ cigarettes daily } \\
\hline & $\mathbf{n}$ & $\%$ & $95 \% \mathrm{Cl}(\%)$ & n & $\%$ & $95 \% \mathrm{Cl}(\%)$ \\
\hline Do not know what they are/Have not tried & 78 & 80.8 & 70.7 to 88.0 & 26 & 65.4 & 46.2 to 80.6 \\
\hline Have tried once or twice & 151 & 76.8 & 69.5 to 82.8 & 73 & 76.7 & 65.8 to 84.9 \\
\hline Have tried 20 times or less & 68 & 73.5 & 62.0 to 82.6 & 43 & 67.4 & 52.5 to 79.5 \\
\hline Have tried more than 20 times & 47 & 55.3 & 41.2 to 68.6 & 37 & 48.6 & 33.4 to 64.1 \\
\hline All & 255 & 74.1 & 69.3 to 78.5 & 179 & 67.0 & 59.9 to 73.5 \\
\hline
\end{tabular}


Table 5 Age and sex adjusted prevalence (\%) of e-cigarette ever use and ORs and the $95 \% \mathrm{Cl}$ for e-cigarette use by tobacco-related and socioeconomic factors, among adolescents aged $14-18$ years

\begin{tabular}{|c|c|c|c|}
\hline Characteristics & $\begin{array}{l}\text { Ever use of } \\
\text { e-cigarettes, \% }\end{array}$ & $\begin{array}{l}\text { Model 1* } \\
\text { OR (95\% Cl) }\end{array}$ & $\begin{array}{l}\text { Model } 2 \dagger \\
\text { OR }(95 \% \mathrm{Cl})\end{array}$ \\
\hline \multicolumn{4}{|l|}{ Tobacco-related factors } \\
\hline \multicolumn{4}{|l|}{ Smoking status } \\
\hline Never $(n=1604)$ & 3.6 & 1.00 & 1.00 \\
\hline Experimenter $(n=994)$ & 32.9 & 14.17 (10.35 to 19.41$)$ & 8.09 (5.56 to 11.78$)$ \\
\hline Daily smoker $(n=350)$ & 81.1 & $120.86(81.72$ to 178.74$)$ & 41.35 (25.22 to 67.79$)$ \\
\hline \multicolumn{4}{|l|}{ Snus use } \\
\hline Never $(n=2373)$ & 11.7 & 1.00 & 1.00 \\
\hline Ever $(n=586)$ & 63.0 & 12.05 (9.69 to 14.98$)$ & 2.96 (2.18 to 4.00$)$ \\
\hline \multicolumn{4}{|l|}{ Waterpipe use } \\
\hline Never $(n=2402)$ & 15.6 & 1.00 & 1.00 \\
\hline Ever $(n=531)$ & 56.0 & 6.54 (5.27 to 8.12$)$ & 2.21 (1.62 to 3.02$)$ \\
\hline \multicolumn{4}{|l|}{ Parents' smoking } \\
\hline Neither of them smokes $(n=1974)$ & 18.6 & 1.00 & NS \\
\hline Only mother smokes $(n=180)$ & 31.4 & 2.23 (1.58 to 3.16$)$ & \\
\hline Only father smokes $(n=381)$ & 28.4 & 1.84 (1.42 to 2.38$)$ & \\
\hline Both of them smoke $(n=237)$ & 33.2 & 2.69 (1.99 to 3.62 ) & \\
\hline \multicolumn{4}{|l|}{ Has seen e-cigarette advertisement } \\
\hline No $(n=2542)$ & 22.0 & 1.00 & NS \\
\hline Yes $(n=335)$ & 30.5 & 1.54 (1.19 to 1.99$)$ & \\
\hline \multicolumn{4}{|l|}{ Statement 'Smoking is for losers' } \\
\hline Agree $(n=1841)$ & 17.2 & 1.00 & NS \\
\hline Hard to say $(n=679)$ & 30.4 & 2.14 (1.74 to 2.64$)$ & \\
\hline Disagree $(n=374)$ & 36.5 & $2.72(2.12$ to 3.50$)$ & \\
\hline \multicolumn{4}{|l|}{ Socioeconomic background } \\
\hline \multicolumn{4}{|l|}{ School } \\
\hline General upper secondary $(n=1165)$ & 18.1 & 1.00 & 1.00 \\
\hline Comprehensive $(n=1077)$ & 19.5 & $1.38(0.77$ to 2.46$)$ & $1.36(0.98$ to 1.89$)$ \\
\hline Vocational upper secondary $(n=520)$ & 51.3 & 3.29 (2.60 to 4.17$)$ & 2.06 (1.43 to 2.97$)$ \\
\hline Combined general and vocational upper secondary/other schools $(n=116)$ & 25.4 & 1.98 (1.28 to 3.05$)$ & 1.31 (0.69 to 2.48 ) \\
\hline Not in school $(n=66)$ & 46.9 & 2.18 (1.26 to 3.76$)$ & 1.40 (0.16 to 12.38$)$ \\
\hline \multicolumn{4}{|l|}{ School performance } \\
\hline Much or slightly better $(n=1431)$ & 16.2 & 1.00 & 1.00 \\
\hline About class average $(n=1132)$ & 25.1 & 1.78 (1.45 to 2.17$)$ & $1.27(0.95$ to 1.69$)$ \\
\hline Slightly or much poorer $(n=319)$ & 41.7 & 3.89 (2.96 to 5.12$)$ & $1.92(1.28$ to 2.90$)$ \\
\hline \multicolumn{4}{|l|}{ Family structure } \\
\hline Intact family ( $n=2308)$ & 20.4 & 1.00 & NS \\
\hline Other family type $(n=650)$ & 29.6 & 1.73 (1.41 to 2.11$)$ & \\
\hline \multicolumn{4}{|l|}{ Parents' educational level } \\
\hline High $(n=1009)$ & 16.7 & 1.00 & NS \\
\hline Middle ( $n=1667)$ & 26.0 & 1.78 (1.45 to 2.19 ) & \\
\hline Low $(n=64)$ & 24.7 & 1.74 (0.96 to 3.18$)$ & \\
\hline \multicolumn{4}{|l|}{ Father's work situation } \\
\hline Working ( $n=2446)$ & 21.5 & 1.00 & NS \\
\hline Not working $(n=357)$ & 27.5 & 1.42 (1.09 to 1.83$)$ & \\
\hline \multicolumn{4}{|l|}{ Mother's work situation } \\
\hline Working ( $n=2570$ ) & 22.0 & 1.00 & NS \\
\hline Not working $(n=310)$ & 28.6 & 1.58 (1.21 to 2.07$)$ & \\
\hline
\end{tabular}

${ }^{*}$ Model 1: logistic regression, adjusted for age and sex.

†Model 2: stepwise forward logistic regression; includes all variables in model 1. Note: OR is given in boldface when it indicates a statistically significant ( $p<0.005$ ) difference from the odds of the reference category.

NS, non-significant.

finding that every 12th adolescent among the e-cigarette ever users was a never-smoker corresponds to evidence from the USA. $^{20}$

E-cigarettes are marketed as a tool for smoking cessation. ${ }^{2} 3$ Despite a growing number of studies among adults, only one study from Korea has previously reported associations between e-cigarette use and smoking cessation in adolescence. ${ }^{18}$ This study found that e-cigarette use was more common among those with a history of recent quit attempts. ${ }^{18}$ Our results suggest a different pattern: e-cigarette use was most common among those tobacco smokers who were least interested in smoking cessation. Further studies are needed to understand the 
relationship between e-cigarette use and smoking cessation in adolescence.

E-liquids containing nicotine are a potential source of nicotine addiction. The use of different types of e-liquids among adolescents has not been previously reported. In our study, most adolescent users of e-cigarettes used e-liquids containing nicotine. A small proportion of nicotine e-liquid users had never tried conventional cigarettes. The possibility of developing nicotine addiction through e-cigarettes cannot be excluded. Further, users may also be exposed to toxic levels of nicotine when refilling cartridges or misusing e-liquids. ${ }^{2}$ Substances other than nicotine could be used, thus delivering drugs with a new device. ${ }^{25}$ Since the majority of e-cigarette users were current daily smokers, concurrent use seems likely to lead to higher nicotine consumption. Dual use is an important topic for further research.

Our results show that adolescents can easily obtain nicotine and non-nicotine e-liquids, despite the prohibition of nicotine e-liquid sales inside Finland. This indicates that more attention should be paid to cross-border distance sales. The main source for e-cigarettes is friends, which may mean purchasing on behalf of friends or sharing. This has not been reported previously. Social sources, particularly friends, are also known to be the most common source for conventional cigarettes. ${ }^{26}$

Despite the Finnish ban on advertising, every 10th adolescent had seen e-cigarette advertisements, mostly on the internet. Several e-cigarette companies have relocated their place of business outside Finland, where they continue advertising to Finnish consumers. Facebook was the only social media website that adolescents mentioned. Advertisements on Facebook can be versatile, ranging from paid commercials to informal groups promoting a specific brand. Interestingly, ever use of e-cigarettes was most common among those who reported seeing an e-cigarette advertisement. Adolescents' knowledge of e-cigarettes can be partly based on marketing messages, which can be misleading. ${ }^{3}$

These results confirm our hypotheses that e-cigarette use is related to tobacco use, with associated factors resembling those of conventional smoking initiation. E-cigarette use was associated with familial socioeconomic disadvantage, vocational school career and poor school performance, which are also risk factors for conventional tobacco smoking. ${ }^{27}$ The meaning of e-cigarettes in adolescents' everyday life may be similar to that of conventional cigarette use since they share similar features. The similarity with patterns of waterpipe and snus use (the first a newcomer, and the second a product with sales prohibition in Finland) suggest that e-cigarettes may appeal to adolescents with novelty-seeking or sensation-seeking characteristics. Another interpretation could be that e-cigarettes appeal to adolescents in the process of forming a smoker identity, a known risk factor for smoking escalation. ${ }^{28}$

Some limitations of our study should be noted. Our data are cross sectional, allowing no causal conclusions. The brief measures of our key constructs may be seen as a limitation since our measures do not capture frequent use of e-cigarettes-only ever use and total episodes of experimentation. Our results are based on adolescents' self-reports, and we cannot know how accurately they answered questions concerning this new phenomenon. The low response rate may compromise the generalisability of the study, although the Finnish arm of the Global Youth Tobacco Survey (conducted a few months earlier among 13-15-year-old adolescents) showed similar age-specific and sex-specific prevalence of e-cigarette use. ${ }^{29}$ Furthermore, our comparison of responders and non-responders found no meaningful difference in use of e-cigarettes.

\section{CONCLUSIONS}

E-cigarette experimentation in adolescence is linked with conventional cigarette use, positive attitudes towards smoking, and experimentation with other tobacco products-indicating novelty-seeking behaviour. E-liquids used by adolescents typically contain nicotine. Factors associated with e-cigarette use are similar to those for conventional smoking initiation. Among smokers, e-cigarette use is associated with lower interest in smoking cessation; never smokers are also shown to use e-cigarettes. These findings challenge claims that the product's sole function is as an adult-oriented smoking cessation or harm reduction tool. Further research is needed to understand adolescents' e-cigarette use in different parts of the world. It will be important to monitor the development of this new phenomenon during the coming years and to develop appropriate policy measures to protect young people from the risks of nicotine addiction. The Framework Convention on Tobacco Control obliges parties to adopt and implement effective measures for preventing and reducing tobacco consumption, and for preventing nicotine addiction. ${ }^{30}$ The new European Tobacco Products Directive sets out important steps for EU-level regulation of e-cigarettes and their marketing. Nevertheless, member states retain responsibility for regulating availability of non-nicotine e-cigarettes and e-liquids, flavours, age limits and use of e-cigarettes in smoke-free environments. For youth protection, additional preventive policies should include age limits, regulation of e-liquid flavours, and efforts to reduce cross-border distance sales.

\section{What this paper adds}

- Awareness and ever use of e-cigarettes appear high among Finnish adolescents, especially in older age groups and boys. E-liquids used in adolescence typically contain nicotine.

- Factors associated with e-cigarette use and sources for e-cigarettes appear similar to those for conventional cigarettes among adolescents.

- Among adolescent smokers, e-cigarette use was the most common among those who were the least interested in smoking cessation. E-cigarettes, even those containing nicotine e-liquid, are also used by those who have never tried conventional tobacco products. These argue against claims that the product is only an adult-oriented smoking cessation or harm reduction tool.

Contributors JK, HO and SEA had the main responsibility for the conduct of this paper. JK, LP, PL and AR were responsible for the planning of the study and for the data collection. LP was responsible for the preparation of the data for analysis. JK and LP were responsible for the statistical analyses. All authors made a substantial contribution to the design and the discussion of the results. All authors participated in writing this paper.

Funding This study was financially supported by the Ministry of Social Affairs and Health (201310 055), Finland, and the Competitive Research Funding of the Tampere University Hospital (9M090), Tampere, Finland.

Competing interests Parts of the salaries of Kinnunen, El-Amin, Pere and Lindfors have been paid with a grant from the Ministry of Social Affairs and Health during the conduct of the study. Rimpelä received a grant from the Ministry of Social Affairs and Health, Finland, and grants from the Competitive Research Fund of Tampere University Hospital during the conduct of the study. Ollila is employed by the National Institute for Health and Welfare, under the Ministry of Social Affairs and Health. There are no conflicts of interest. 
Ethics approval The Ethics Committee of the Tampere region, Finland.

Provenance and peer review Not commissioned; externally peer reviewed.

Open Access This is an Open Access article distributed in accordance with the Creative Commons Attribution Non Commercial (CC BY-NC 3.0) license, which permits others to distribute, remix, adapt, build upon this work non-commercially, and license their derivative works on different terms, provided the original work is properly cited and the use is non-commercial. See: http://creativecommons.org/ licenses/by-nc/3.0/

\section{REFERENCES}

1 WHO Study Group on Tobacco Product Regulation. Report on the Scientific Basis of Tobacco Product Regulation: Third Report of a WHO Study Group. WHO technical report series 955. Geneva: World Health Organization, 2009.

2 WHO Tobacco Free Initiative. Questions and answers on electronic cigarettes or electronic nicotine delivery systems (ENDS). Statement, 9 July 2013.

3 Grana RA, Linq PM. 'Smoking revolution': a content analysis of electronic cigarette retail websites. Am J Prev Med 2014;46:395-403.

4 Bullen $C$, Howe $C$, Lauqesen $M$, et al. Electronic cigarettes for smoking cessation: a randomised controlled trial. Lancet 2013:382:1629-37.

5 Connolly GN, Alpert HR. Has the tobacco industry evaded the FDA's ban on 'Light' cigarette descriptors? Tob Control 2014;23:140-5.

6 McKee M. E-cigarettes and the marketing push that surprised everyone. BMJ 2013;347:f5780.

7 Cobb NK, Brookover J, Cobb CO. Forensic analysis of online marketing for electronic nicotine delivery systems. Tob Control 2015;24:128-31.

8 Lovato C, Watts A, Stead LF. Impact of tobacco advertising and promotion on increasing adolescent smoking behaviours. Cochrane Database Syst Rev 2011;(10): CD003439.

9 Yamin CK, Bitton A, Bates DW. E-Cigarettes: a rapidly growing internet phenomenon. Ann Intern Med 2010;153:607-9.

10 Westenberger BJ. Evaluation of E-cigarettes. Rockville, MD: US Food and Drug Administration, Center for Drug Evaluation and Research, Division of Pharmaceutical Analysis, 2009.

11 Trehy ML, Ye W, Hadwiger ME, et al. Analysis of electronic cigarette cartridges, refill solutions, and smoke for nicotine and nicotine related impurities. J Liq Chromatogr Relat Technol 2011;34:1442-58.

12 Williams M, Talbot P. Variability among electronic cigarettes in the pressure drop, airflow rate, and aerosol production. Nicotine Tob Res 2011;13:1276-83.

13 Etter JF, Zäther $E$, Svensson $S$. Analysis of refill liquids for electronic cigarettes. Addiction 2013;108:1671-9.
14 Vardavas Cl, Anagnostopoulos N, Kougias M, et al. Short-term pulmonary effects of using an e-cigarette: impact on respiratory flow resistance, impedance and exhaled nitric oxide. Chest 2012;141:1400-6.

15 Poorthuis RB, Goriounova NA, Couey JJ, et al. Nicotinic actions on neuronal networks for cognition: general principles and long-term consequences. Biochem Pharmacol 2009;78:668-76.

16 O'Dell LE. A psychobiological framework of the substrates that mediate nicotine use during adolescence. Neuropharmacology 2009;56(Suppl 1):263-78.

17 DiFranza JR, Savageau JA, Fletcher K, et al. Symptoms of tobacco dependence after brief intermittent use: the development and assessment of nicotine dependence in Youth-2 study. Arch Pediatr Adolesc Med 2007;161:704-10.

18 Lee S, Grana RA, Glantz SA. Electronic cigarette use among Korean adolescents: a cross-sectional study of market penetration, dual use, and relationship to quit attempts and former smoking. J Adolesc Health Published Online First: 22 Nov 2013. doi:10.1016/j.jadohealth.2013.11.003

19 Goniewicz ML, Zielinska-Danch W. Electronic cigarette use among teenagers and young adults in Poland. Pediatrics 2012;130:e879-85.

20 Centers for Disease Control and Prevention (CDC). Notes from the field: electronic cigarette use among middle and high school students-United States, 2011-2012. MMWR Morb Mortal Wkly Rep 2013;62:729-30.

21 Camenga DR, Delmerico J, Kong G, et al. Trends in use of electronic nicotine delivery systems by adolescents. Addict Behav 2014;39:338-40.

22 Pepper JK, Reiter PL, McRee AL, et al. Adolescent males' awareness of and willingness to try electronic cigarettes. J Adolesc Health 2013;52:144-50.

23 Pepper JK, Brewer NT. Electronic nicotine delivery system (electronic cigarette) awareness, use, reactions and beliefs: a systematic review. Tob Control 2014;23: 375-84.

24 European Commission. Attitudes of Europeans Towards Tobacco. Special Eurobarometer 385. May 2012.

25 National Institute on Drug Abuse (NIDA). Drug Facts. US Department of Health and Human Services, National Institutes of Health, 2013.

26 Rainio SU, Rimpelä AH. Home-based sourcing of tobacco among adolescents. Prev Med 2009;48:378-82.

27 Pennanen $\mathrm{M}$, Haukkala $\mathrm{A}$, de Vries $\mathrm{H}$, et al. Longitudinal study of relations between school achievement and smoking behavior among secondary school students in Finland: results of the ESFA study. Subst Use Misuse 2011;46:569-79.

28 Hertel AW, Mermelstein RJ. Smoker identity and smoking escalation among adolescents. Health Psychol 2012;31:467-75.

29 Centers for Disease Control and Prevention (CDC), World Health Organization (WHO), National Institute for Health and Welfare (THL). Global Youth Tobacco Survey: Factsheet Finland 2012.

30 WHO. Framework Convention on Tobacco Control. Geneva: World Health Organization, 2003. 